\title{
The Role of Magnetic Resonance Imaging in Evaluation of Leiomyoma after Uterine Artery Embolization
}

\author{
MOUNIR S. GUIRGUIS, M.D.; ALLAM E. ALLAM, M.D. and DALIA S.M. SAEED, M.Sc. \\ The Department of Radiodiagnosis, Faculty of Medicine, Ain Shams University
}

\begin{abstract}
Background: Uterine leiomyomas are the most common benign tumours in women and accounts for the majority of hysterectomies in the world. MR imaging performed before and after uterine artery embolization is the best imaging modality to diagnose, map, and characterize fibroids.

Aim of Study: To emphasize the utility of MR imaging in the post-procedural assessment for uterine leiomyomas patients who underwent uterine artery embolization.

Patients and Methods: A retrospective study was carried out on 15 patients who underwent MRI scan as a six-month follow-up after uterine artery embolization for treating uterine fibroids during the period from October 2018 to March 2019.

Results: The mean uterine volume was significantly reduced by $61 \%$ ( $p$-value 0.015$)$, the mean dominant fibroids volume significantly reduced by $79 \%$ ( $p$-value 0.004$)$ and the dominant fibroids showed significant lack of enhancement $100 \%$ ( $p$-value $<0.001)$ that indicted treatment success and in assessing the outcomes and complications as only $1(6.7 \%)$ patient detected with pyometra (uterine infection). In this study we noted significant improvement of bleeding in $69.2 \%$ and of pain in $11.1 \%$ with slight improvement of pressure symptoms in $66.7 \%$.
\end{abstract}

Conclusion: 6-month follow-up MRI has an important role in evaluation of UAE success through uterine and dominant fibroid volume reduction and lack of enhancement, and evaluation of the outcomes and complications including fibroid regrowth, fibroid change site, pyometra and uterine necrosis.

Key Words: MRI - Uterine leiomyomas - Uterine artery embolization.

\section{Introduction}

UTERINE fibroids or leiomyomas are the most prevalent benign uterine tumors with an incidence rate of $20 \%-40 \%$ during women reproductive life [1].

Correspondence to: Dr. Mounir S. Guirguis, The Department of Radiodiagnosis, Faculty of Medicine, Ain Shams University
Management of symptomatic uterine fibroids have been traditionally including different treatments ranging from medical treatment up to invasive hysterectomy [2].

When the medical treatment give unsatisfying results in patients with symptomatic uterine fibroids; hysterectomy are used to be an option, which is an invasive procedure that is coupled with significant morbidities, $10-15 \%$ complication rates as well as lengthy hospital stay and prolonged recovery time [3].

Laparoscopic and hysteroscopic myomectomy appear as a useful option for women who have not already completed having children or those who wish to retain their uterus and their fertility, but the inoperability of multiple fibroids and high recurrence rate for the operable ones that will require additional surgical intervention make it unfeasible in all cases [4].

Uterine Artery Embolization (UAE) is a minimally invasive alternative option for management of symptomatic leiomyomas [5]

It was first reported as an effective uterine bleeding treatment option in 1995 and then it has been proven to be an efficacious and safe method with a relatively high success rate in minimizing pain, bulk symptoms and bleeding linked to uterine fibroids. UAE is increasingly being preferred over surgical hysterectomy or myomectomy due to reduced morbidity, shorter hospitalization, and relative uterine preservation when compared to surgical resolution [6]

Leiomyomas are hyper vascular benign lesions with large vessels supplying higher vascular flow relative to the normal myometrial vasculature. This permits preferential targeting and occlusion of end 
arterial branches that perfuse leiomyomas during the delivery of the particulate embolization agent used during UAE. Embolization of these end arterial branches ultimately results in infarction, coagulative necrosis, and eventual shrinkage of the targeted leiomyomas [7]

Magnetic Resonance Imaging (MRI) is the preferable modality over transvaginal ultrasound in the pre-and post-procedural evaluation for UAE due to its higher accuracy in assessing site and size of uterine leiomyomas [8]

Moreover, MRI is more sensitive than ultrasound in diagnosing and excluding further causes of pelvic pain like adenomyosis or endometriosis [7].

MRI plays an important role in post-procedural follow-up for treatment response assessment, failure or recurrence, and detection for any procedural complication [9].

\section{Aim of the study:}

The aim of this study is to emphasize the utility of MR imaging in the post-procedural assessment for uterine leiomyomas patients who underwent Uterine artery embolization (UAE).

\section{Patients and Methods}

\section{A- Patients:}

This retrospective study involved 15 women patients underwent MRI scan as a six months follow-up after uterine artery embolization for treating uterine fibroids.

Patients age range of 21-45 years with (mean \pm SD) of (37.20 \pm 6.87$)$ years.

This study was carried out in the period from October 2018 to March 2019.

The data was executed from Body Imaging Unit, Radio-Diagnosis Department, Faculty of Medicine, Ain Shams University Hospitals and specialized private radiology centres. The patients were referred from different interventional radiologist centers for MRI pre and 6 months post uterine artery embolization.

\section{Inclusion criteria:}

The patients who underwent Uterine Artery Embolization (UAE) for symptomatic uterine leiomyomas and follow-up pelvic MRI at least 6 months following the procedure.

\section{Exclusion criteria:}

No absolute exclusion criteria.
The study was approved by Ethical Committee of Faculty of Medicine, Ain Shams University with exemption from ethical consent as the stored data had been used.

\section{B- Methods:}

All patients had MRI scan six months post uterine fibroid embolization with baseline pre procedural MRI.

MRI scans are considered to be a safe procedure. Side effects or reactions are uncommon but may occur.

1- The most common adverse reactions are brief headache, nausea and dizziness for a brief time following the contrast injection.

2- Anaphylactic reactions to Gd contrast medium but they are extremely rare.

3- Rare occurrence of nephrogenic systemic fibrosis in minority of patients who had pre-existing severe renal function abnormalities.

Management in cases of risks and complications:

1- Bed rest following the procedure is sufficient for headache, nausea coupled with analgesic if necessary.

2- Adequate hydration.

3- Premedication with steroids. Epinephrine (1: $1,000) 0.5 \mathrm{ml}$ subcutaneously if no cardiac contraindications in the acute incident.

Procedures:

All patients were subjected for:

1-Proper history taking and full clinical assessment.

2- Pre-procedural assessment of renal function including blood urea and serum creatinine.

3- Total fasting for six hours.

4- Administration of an ante-cubital intravenous catheter.

5- Received a single dose of 20mg Buscopan intramuscular injection, in order to minimize artifacts caused by bowel motion.

MR images were obtained with a 1.5-Tesla Philips Insignia (Philips Healthcare)with highperformance gradient systems and phased array body coil. The study took about 20-30 minutes. The patient was positioned supine on the MRI table (Head first).

An intravenous bolus of contrast gadolinium $(0.1 \mathrm{mmol} / \mathrm{kgbody}$ weight $)$ was administered to the patient at ehe post contrast sequences. 
Pre-and post-embolization MRI evaluation were performed utilizing the identical protocol. Axial T1 weighted fast spin-echo sequences (TR 400$600 \mathrm{~ms}$, TE $12 \mathrm{~ms}$, flip angle $95^{\circ}$, matrix 184 X 182 , $5 \mathrm{~mm}$ slices). Axial, sagittal, and coronal fast spinecho T2 weighted sequences (TR 3000/5000, TE $100 \mathrm{~ms}$, flip angle $90^{\circ}$, matrix $200 \times 196$, slice thickness 5mm). Axial, sagittal, and coronal T1weighted fat-suppressed pre-and post-contrast imaging were obtained (TR 660, TE $9.5 \mathrm{~ms}$, flip angle $90^{\circ}$, matrix $184 \times 182$, slice thickness $5 \mathrm{~mm}$ ). Field of view was axial $(20-24 \mathrm{~mm}$ fit to patient, scan iliac crest to perineum), sagittal ( $24 \mathrm{~mm}$ fit to patient, scan mid femoral head to mid femoral head), and coronal (top of kidneys to pelvis, scan sacrum to anterior abdominal wall).

T1-weighted images provided an anatomic overview of the pelvis for characterization of incidental pelvic abnormalities. Non-enhanced T1weighted fat-suppressed imaging was useful in identifying blood products, which suspected to be seen with hemorrhagic degeneration of leiomyomas or with adenomyosis or endometriosis. In addition T1-weighted fat-suppressed images also were helpful in distinguishing lesions with high signal such as dermoids which lose signal in fat suppression.

T2-weighted sequences delineated the zonal anatomy of the uterus and allowed for accurate localization of the leiomyomas. The outer most myometrium was intermediate signal, the junctional zone was hypo intense and the innermost endometrial strip was hyper intense, and gave a clue about the uterine fibroid degeneration state.

Contrast-enhanced imaging was essential in determining the vascularity and viability of the targeted leiomyomas, and aided in detection of degenerated fibroids from high cellular non degenerated fibroids.

Theresults of pre procedural pelvic MRI with contrast were used as a baseline for comparison with those of the postprocedural examination considering the uterine fibroids location and number, uterine and dominant fibroid volumes, and fibroid enhancement as well as complications.

Uterine and dominant fibroid volumes assessed by measuring the three dimensions and performing the volume equation (volume=length $\mathrm{X}$ width $\mathrm{X}$ depth X 0.52).

Enhancement state of the fibroid in T1 post contrast weighted imaging that revealed the vascularity and viability of the fibroid post procedure was evaluated, as the non enhancement reflected treatment success.

Atypical outcomes or complications included as fibroid site change, regrowth of fibroid (in form of increased volume of the dominant lesion or appearance of new fibroids), pyometra appeared as air jet black color within uterine wall, and necrosis.

Moreover, the clinical data collected from the interventional radiologist about the patients' symptoms improvement 6 months after the procedure by verbal questionnaire was considered. The bleeding, pressure and pain symptoms improvements were graded as follows: Significantly worse (1), slightly worse (2), stationary (3), slightly improved (4), significantly improved (5).

The uterine fibroid shrinkage volume from preand post-procedural MRI scans was correlated with symptomatic improvement/deterioration or stability to test the association significance between radiological MRI improvement and symptomatic amelioration.

Recorded data were analyzed using the statistical package for social sciences, Version 20.0 (SPSS Inc., Chicago, Illinois, USA). Quantitative data were expressed as mean \pm Standard Deviation (SD). Qualitative data were expressed as frequency and percentage.

\section{The following tests were done:}

1- Paired sample $t$-test of significance was used when comparing between related samples.

2- Chi-square $\left(\chi^{2}\right)$ test of significance was used in order to compare proportions between qualitative parameters.

3- The confidence interval was set to $95 \%$ and the margin of error accepted was set to 5\%. So, the Probability $p$-value was considered significant as the following:

- $p$-value $<0.05$ was considered significant.

$\bullet p$-value $<0.001$ was considered as highly significant.

- $p$-value $>0.05$ was considered insignificant.

\section{Results}

The most common presenting symptom of the uterine fibroids was abnormal bleeding in 13 $(86.7 \%)$ patients; $4(30.8 \%)$ of them got slightly improved and $9(69.2 \%)$ were significantly improved 6 months post UAE. These results are statistically significant and reflects the positive effect of UAE in bleeding improvement (Table 1). 
Table (1): Bleeding distribution and improvement at the study group.

\begin{tabular}{llc}
\hline \multicolumn{1}{c}{ Bleeding } & No. & $\%$ \\
\hline \multicolumn{1}{c}{ No } & 2 & 13.3 \\
\multicolumn{1}{c}{ Yes } & 13 & 86.7 \\
\hline Improvement score & No. & $p$-value \\
\hline Significantly worse & $0(0 \%)$ & - \\
Slightly worse & $0(0 \%)$ & - \\
Stationary & $0(0 \%)$ & $0.009^{*}$ \\
Slightly improved & $4(30.8 \%)$ & $<0.001 * *$ \\
Significantly improved & $9(69.2 \%)$ & \\
\hline$p$-value $>0.05$ NS. $*: p$-value $<0.05$ S. $* *: p$-value $<0.001 \mathrm{HS}$.
\end{tabular}

Pressure symptoms were presented in $9(60 \%)$ patients, 3 of them $(33.3 \%)$ showed stationary state and $6(66.7 \%)$ got slightly improved after 6 months, this is statistically significant indicating the positive effect of UAE in pressure symptoms improvement (Table 2).

Table (2): Effect of UAE on pressure symptoms at the study group.

\begin{tabular}{lcc}
\hline \multicolumn{1}{c}{ Pressure symptoms } & No. & $\%$ \\
\hline \multicolumn{1}{c}{ No } & 6 & 40.0 \\
\multicolumn{1}{c}{ Yes } & 9 & 60.0 \\
\hline Improvement score & No. & $p$-value \\
\hline Significantly worse & $0(0 \%)$ & - \\
Slightly worse & $0(0 \%)$ & \\
Stationary & $3(33.3 \%)$ & $0.032^{*}$ \\
Slightly improved & $6(66.7 \%)$ & $0.013^{*}$ \\
Significantly improved & $0(0 \%)$ & - \\
\hline
\end{tabular}

$p$-value $>0.05 \mathrm{NS} . *$ : $p$-value $<0.05 \mathrm{~S} . \quad * *: p$-value $<0.001 \mathrm{HS}$.

Pain was present in $9(60 \%)$ patients. Six months after UAE, 2 (22.2\%) patients were stationary, $6(66.7 \%)$ patients got slight improvement, and only $1(11.1 \%)$ patient significantly improved.

There was statistically significant results in patients with stationary state and slight improvement pointing to the positive effect of UAE in pain improvement as two third of the symptomatic patients were slightly improved (Table 3).

Table (3): The impact of UAE on pain at the study group.

\begin{tabular}{llc}
\multicolumn{1}{c}{ Pain } & No. & \multicolumn{2}{c}{$\%$} \\
\hline \multicolumn{1}{c}{ No } & 6 & 40.0 \\
\multicolumn{1}{c}{ Yes } & 9 & 60.0 \\
\hline Improvement score & No. & $p$-value \\
\hline Significantly worse & $0(0 \%)$ & - \\
Slightly worse & $0(0 \%)$ & $0.044^{*}$ \\
Stationary & $2(22.2 \%)$ & $0.003^{*}$ \\
Slightly improved & $6(66.7 \%)$ & 0.148 \\
Significantly improved & $1(11.1 \%)$ & \\
\hline
\end{tabular}

Women seeking for pregnancy were $2(13.3 \%)$ patients, with stationary state 6 months post UAE, which was statistically significant reflecting equivocal effect of UAE on fertility (Table 4).

Table (4): Effect of UAE on pregnancy seeking at the study group.

\begin{tabular}{lcc}
\hline \multicolumn{1}{c}{ Seeking for pregnancy } & No. & $\%$ \\
\hline \multicolumn{1}{c}{ No } & 13 & 86.7 \\
\multicolumn{1}{c}{ Yes } & 2 & 13.3 \\
\hline Improvement score & No. & $p$-value \\
\hline Significantly worse & $0(0 \%)$ & - \\
Slightly worse & $0(0 \%)$ & - \\
Stationary & $2(100 \%)$ & $0.029^{*}$ \\
Slightly improved & $0(0 \%)$ & - \\
Significantly improved & $0(0 \%)$ & - \\
\hline
\end{tabular}

$p$-value $>0.05$ NS

$*: p$-value $<0.05 \mathrm{~S}$

**: $p$-value $<0.001 \mathrm{HS}$.

There was statistically significant volume reduction post UAE that indicated procedure success (Table 5), Fig. (1).

Table (5): Comparison between pre and post UAE according to the mean volume of the uterus $/ \mathrm{cm} 3[$ mean $\pm \mathrm{SD}]$.

\begin{tabular}{lllcc}
\hline MRI & $\begin{array}{c}\text { Pre } \\
\text { procedure }\end{array}$ & $\begin{array}{c}\text { Post } \\
\text { procedure }\end{array}$ & $\begin{array}{c}\text { Paired } \\
t \text {-test }\end{array}$ & $\begin{array}{c}p \text { - } \\
\text { value }\end{array}$ \\
\hline $\begin{array}{l}\text { Volume of the } \\
\text { uterus } / \mathrm{cm}^{3} \text { : }\end{array}$ & & & & \\
$\quad$ Mean $\pm \mathrm{SD}$ & $637.53 \pm$ & $249.67 \pm$ & 2.581 & $0.015^{*}$ \\
& 350.63 & 185.65 & & \\
\hline
\end{tabular}

$*$ : $p$-value $<0.05 \mathrm{~S}$.

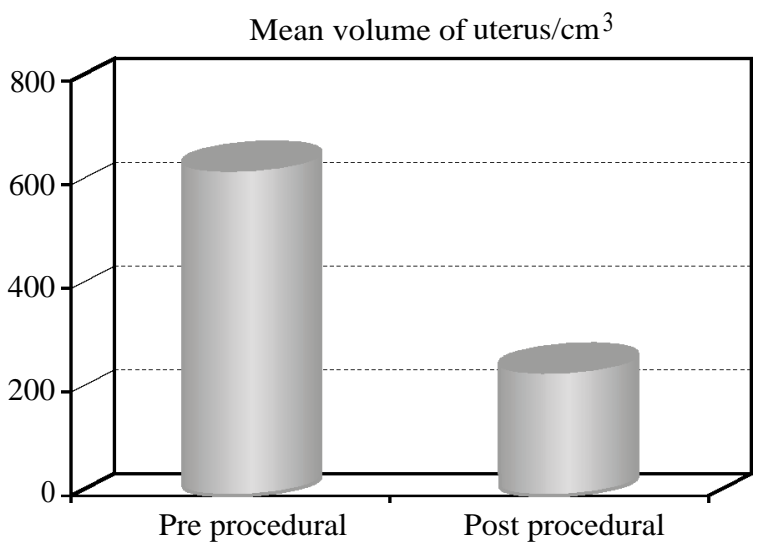

Fig. (1): Bar chart comparing the mean volume of the uterus pre and post UAE.

There was statistically significant volume reduction between pre and post procedure dominant fibroid volume $/ \mathrm{cm}^{3}$ that indicated procedural success (Table 6), Fig. (2). 
Table (6): Comparison between pre and post UAE according to mean volume of the dominant fibroid $/ \mathrm{cm}^{3}[$ mean $\pm \mathrm{SD}]$.

\begin{tabular}{lllll}
\hline MRI & $\begin{array}{c}\text { Pre } \\
\text { procedure }\end{array}$ & $\begin{array}{c}\text { Post } \\
\text { procedure }\end{array}$ & $\begin{array}{c}\text { Paired } \\
t \text {-test }\end{array}$ & $\begin{array}{c}p \text { - } \\
\text { value }\end{array}$ \\
\hline $\begin{array}{l}\text { Volume of the } \\
\text { dominant fibroid } / \mathrm{cm}^{3}:\end{array}$ & & & & \\
Mean $\pm \mathrm{SD}$ & $341.0 \pm$ & $75.56 \pm 3.995$ & $0.004^{*}$ \\
& 262.73 & 56.64 & & \\
\hline
\end{tabular}

$*$ : $p$-value $<0.05 \mathrm{~S}$.

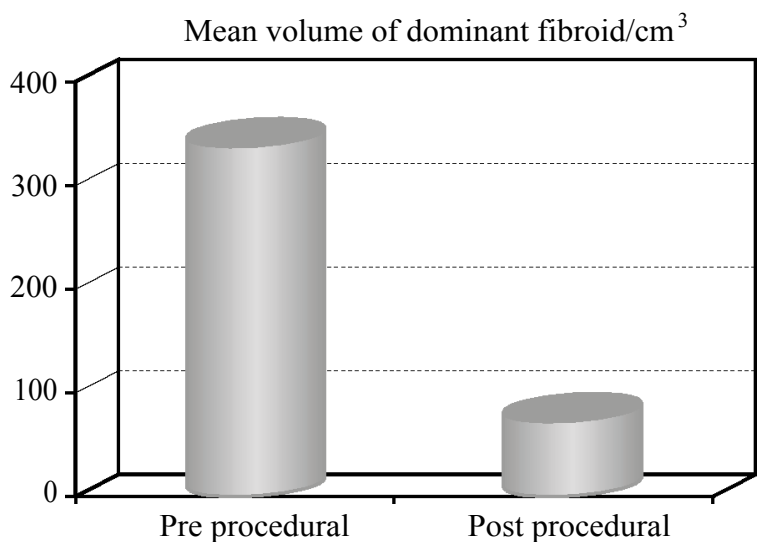

Fig. (2): Bar chart comparing the mean volume of the dominant fibroid pre and post UAE.

A high statistically significant dominant fibroid enhancement difference between pre and post UAE was noted as all the dominant fibroidschanged from pre procedure enhanced to post procedure non enhanced lesions that confirmed UAE success (Table 7).

Table (7): Comparison between pre and post UAE according to the dominant fibroid enhancement.

\begin{tabular}{lllcl}
\hline $\begin{array}{l}\text { Dominant } \\
\text { fibroid } \\
\text { Enhancement }\end{array}$ & $\begin{array}{c}\text { Pre } \\
\text { procedure }\end{array}$ & \multicolumn{1}{c}{$\begin{array}{c}\text { Post } \\
\text { procedure }\end{array}$} & $\begin{array}{c}\text { Chi- } \\
\text { square } \\
\text { test }\end{array}$ & $\begin{array}{c}p \text { - } \\
\text { value }\end{array}$ \\
\hline Positive & $15(100 \%)$ & $0(0 \%)$ & 30.000 & $<0.001^{* *}$ \\
Negative & $\mathbf{0}(0 \%)$ & $15(100 \%)$ & & \\
\hline
\end{tabular}

**: $p$-value $<0.001$ HS.

One patient only showed complication post UAE, that had pyometra (uterine infection) (Table 8), Fig. (3).

Table (8): Complications after UAE.

\begin{tabular}{lll}
\hline Complications & No. & $\%$ \\
\hline Yes & 1 & 6.7 \\
No & 14 & 93.3 \\
Fibroid regrowth & 0 & 0.0 \\
Fibbroid site changes & 0 & 0.0 \\
pyometra (uterine infection) & 1 & 6.7 \\
Uteine necrosis & 0 & 0.0 \\
\hline
\end{tabular}

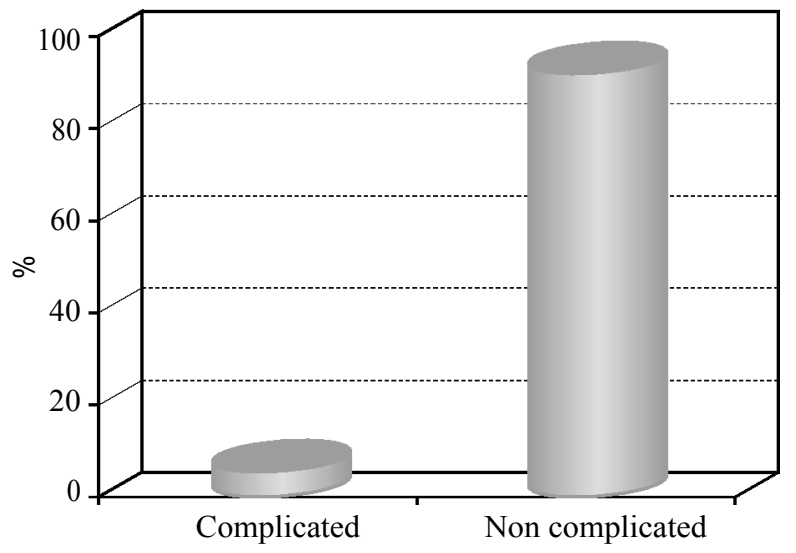

Fig. (3): Bar chart shows complications after UAE.

Uterine volume change percentage showed no significant correlation with bleeding, pressure symptoms, and pain improvement scores. While the correlation between uterine volume change percentage and improvement score of the fertility was precluded as fertility improvement needs long time up to one year at least in order to shows change according to the gynaecological definition, and as our 6 months post UAE follow-up shows stationary state (Table 9).

Table (9): Correlation between pre to post procedure change in percentage of uterine volume $/ \mathrm{cm}^{3}$ with improvement score of signs and symptoms, using Pearson correlation coefficient.

The improvement score

Volume of uterus $/ \mathrm{cm}^{3}$ of signs and symptoms Change \%

\begin{tabular}{ll}
\hline Improvement score of bleeding: & \\
$r$ & -0.161 \\
$p$-value & 0.567
\end{tabular}

Improvement score of pressure symptoms:

$r$

$p$-value

Improvement score of pain:

$\begin{array}{ll}r & 0.101 \\ p \text {-value } & 0.796\end{array}$

$r$-Pearson correlation coefficient.

$p$-value $>0.05 \mathrm{NS}$.

$*$ : $p$-value $<0.05 \mathrm{~S}$.

$* *$ : $p$-value $<0.001 \mathrm{HS}$

Dominant fibroid volume change percentage showed no significant correlation with bleeding, pressure symptom, and pain improvement scores. While the correlation between dominant fibroid volume change percentage and improvement score of the fertility was precluded (Table 10). 


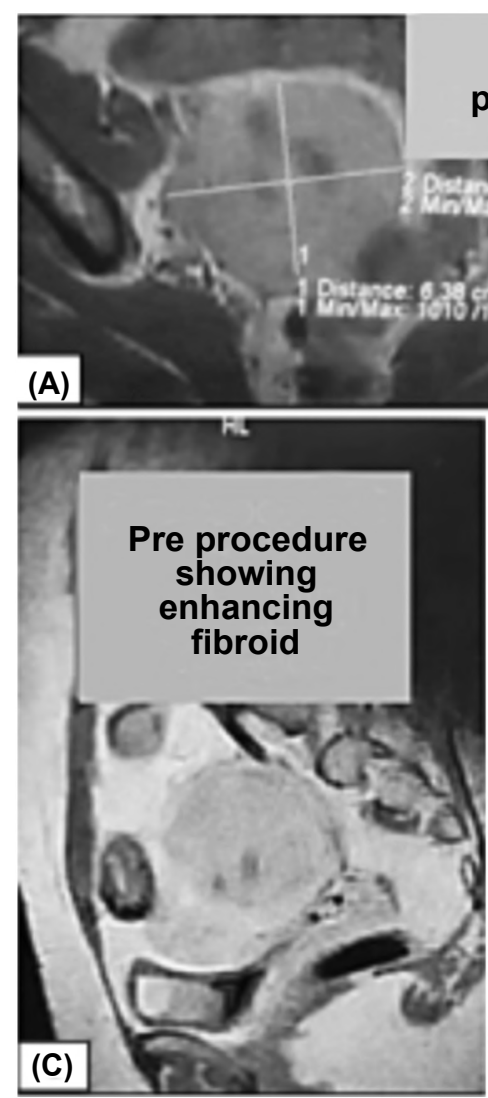

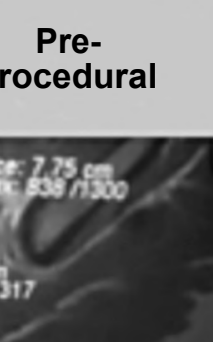

10

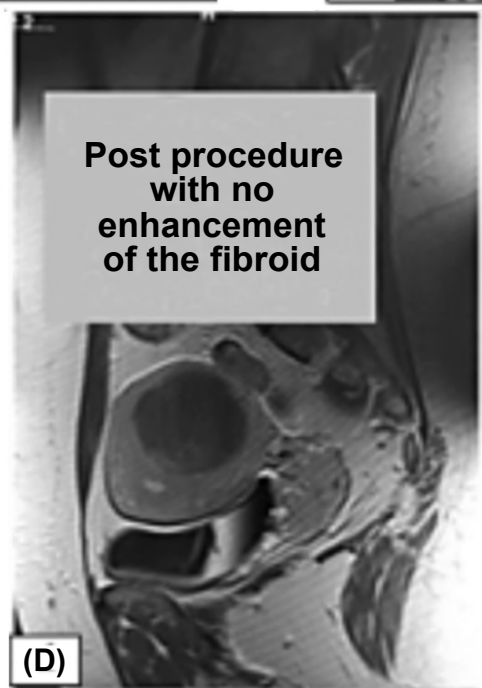

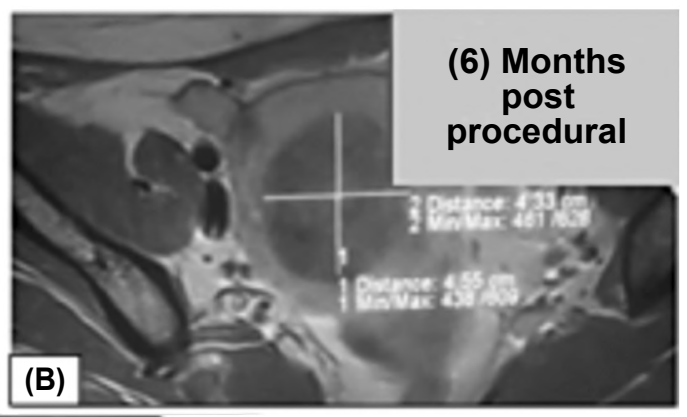

Fig. (4): A 38 years old female patient had a history of severe menorrhagia, after UAE highly significant improvement of bleeding noted with no evidence of complications. (A, C) T1 weighted MRI after gadolinium contrast injection axial and sagittal sections respectively show a solitary intramural homogenous intensily enhancing posterior wall fibroid of average volume $88 \mathrm{~cm}$, (B, D) Postembolization T1 weighted MRI after gadolinium contrast injection axial and sagittal sections respectively show a significant reduction in fibroid volume of about $39 \mathrm{~cm}^{3}$ with lack of contrast enhancement concordant with infarction.
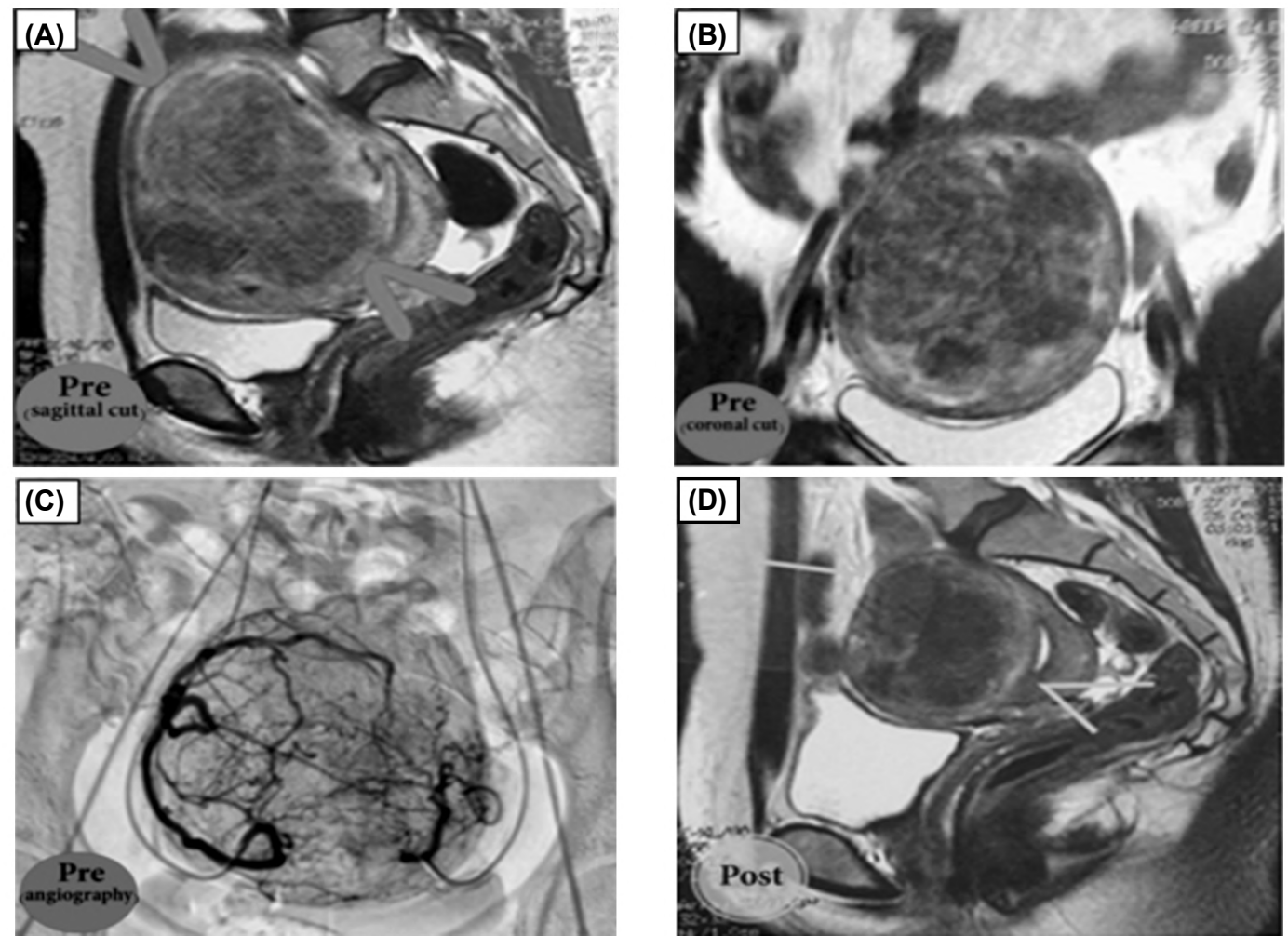

Fig. (5): A 44 years old female patient had a history of severe recurrent attacks of bleeding associated with pelviabdominal pain and pressure symptoms presented as frequent urination, after UAE slight symptomatic improvement of bleeding, pain, and pressure symptoms and no evidence of complications. (A, B) Sagittal and coronal sections respectively of T2 weighted MRI showed a solitary intramural heterogeneous signal intensity anterior wall uterine fibroid of average volume $928 \mathrm{~cm}^{3}$ (red arrow head), (C) Digital subtraction angiography showed fibroid blood supply by both uterine arteries with major contribution from the right side, (D) Post-embolization sagittal T2 weighted MRI showed a significant reduction in fibroid volume reach to $343 \mathrm{~cm}^{3}$ (green arrow head). 


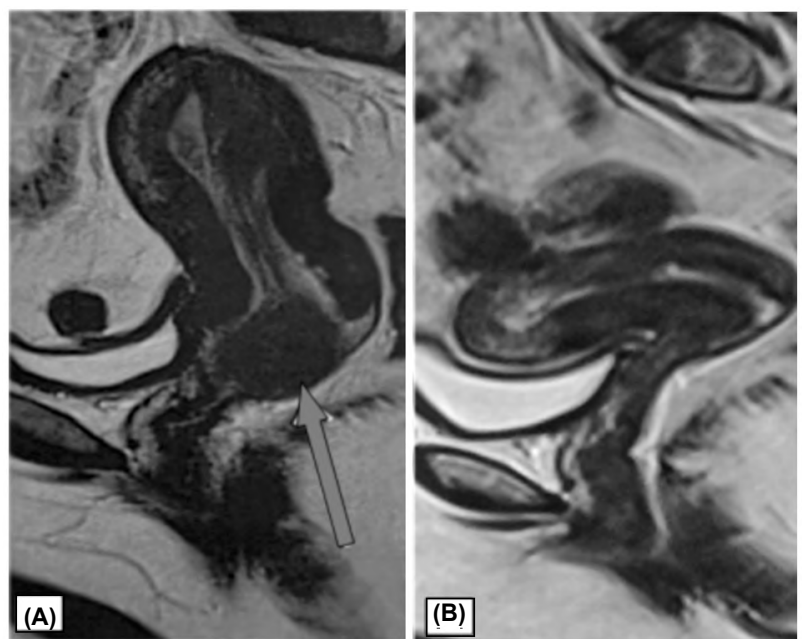

Fig. (6): A young lady of 21 years old unmarried patient had a history of menorrhagia, after UAE bleeding subset with no evidence of complications. (A) Sagittal T2 weighted MRI showed a solitary homogenous low signal intensity intramural cervical fibroid of average volume $1.5 \mathrm{~cm}^{3}$ (red arrow). (B) Post-embolization sagittal T2 weighted MRI showed a complete disappearance of the fibroid.
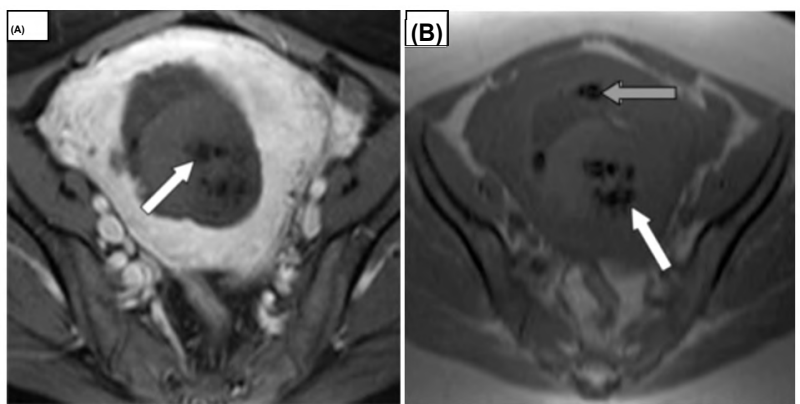

Fig. (7): A 34 years old female patient had a history of pressure symptoms and seeking for fertility, after UAE complication assessed as pyometra, while the symptomatic improvement assessment recorded as slight improvement for the pressure symptoms and stationary for the fertility state. Post UAE MRI (A) Axial post contrast fat-suppressed T1 weighted imaging showed non enhanced fibroid about $75 \mathrm{~cm}^{3}$ with air foci of signal void within the fibroid (white arrow). (B) Axial T1 weighted imaging showed air foci of signal void within the fibroid (white arrow) and uterine wall (red arrow), diagnosed as pyometra (uterine infection).

Table (10): Correlation between pre to post procedure change in percentage of dominant fibroid volume $/ \mathrm{cm}^{3}$ with improvement score of signs and symptoms, using Pearson correlation coefficient.

\begin{tabular}{lc}
\hline $\begin{array}{l}\text { Sign and symptoms with the } \\
\text { improvement score for each one }\end{array}$ & $\begin{array}{c}\text { Volume of dominant } \\
\text { fibroid } / \mathrm{cm} \text { Change } \%\end{array}$ \\
\hline $\begin{array}{l}\text { Improvement score of bleeding: } \\
r\end{array}$ & -0.150 \\
$\quad$-value & 0.592 \\
$\begin{array}{l}\text { Improvement score of } \\
\text { pressure symptoms: }\end{array} \quad$ \\
$r$-value & -0.323 \\
$\quad$ & 0.323 \\
Improvement score of pain: & \\
$r$ & -0.079 \\
$p$-value & 0.840 \\
\hline$r$-Pearson correlation coefficient. & $*: p$-value $<0.05 \mathrm{~S}$. \\
$p$-value $>0.05$ NS. & $* *: p$-value $<0.001 \mathrm{HS}$.
\end{tabular}

\section{Discussion}

In our study the clinical presentation of patients gained though data collected from the radiology specialists' saved archived cases about pre and post patients follow-up, showed that $13(86.7 \%)$ patients have bleeding pre UAE, with $4(30.8 \%)$ patients showed slight improvement while 9 (69.2\%) patients significantly improved post UAE. These are statistically significant with $p$-values of 0.009 and $<0.001$ respectively. Also in our study,the pressure symptomswere present in $9(60 \%)$ patients pre UAE, with $3(33.3 \%)$ patients remained stationary and $6(66.7 \%)$ patients showed slight improvement post UAE, which were statistically significant with $p$-values of 0.032 and 0.013 respectively. That was congruent with the results of Kim et al., [10] study of 5 years long-term that found $85 \%$ to $95 \%$ of patients reported a reduction in menorrhagia, and 40 to $60 \%$ of patients reported a reductions in bulkrelated symptoms. Also Liang et al., [5] stated nearly similar results with improvement of $96 \%$ for menorrhagia, and $50 \%$ had resolution of all urinary symptoms.

In our study $9(60 \%)$ patients had pain pre UAE, and after the procedure $2(22.2 \%)$ patients were stationary, $6(66.7 \%)$ patients were slightly improved and only $1(11.1 \%)$ patient was significantly improved, which is statistically significant with $p$-values of $0.044,0.003$ and 0.148 respectively. And is consistent with Liang et al., [5] study that reported that $56 \%$ of the patients had resolution of pain.

In our study $2(13.3 \%)$ patients were seeking for fertility pre UAE, and showed stationary state of fertility post UAE at 6 months follow-up; and may need further time follow-up in hope of getting conceive. This is unlikely statistically significant $p$-value of 0.029 . On the other hand, Homer and Saridogan [11] reported that $50 \%$ of women who tried to conceive after UAE became pregnant, the live birth rate was $19 \%$ while the rate of spontaneous abortion was $64 \%$ in women who conceived, however there was no obstetric complications which included preterm delivery, malpresentation, and intrauterine growth retardation in the ongoing pregnancies. While Goldberg et al., [12] in a retrospective study revealed that patients have higher preterm and mal-presentation rates after UAE.

In this study, the range [mean $\pm \mathrm{SD}$ ] of the uterine and dominant fibroid volume $/ \mathrm{cm}^{3}$ pre UAE

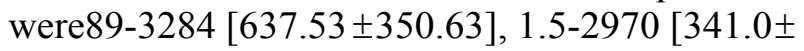
$262.73]$ respectively, and the range [mean $\pm \mathrm{SD}$ ] of the uterine and dominant fibroid volume $/ \mathrm{cm} 3$ 
post UAE were 55-597 [249.67 \pm 185.65$], 0-343$ [75.56 \pm 56.64$]$ respectively. With statistically significant difference between pre and post procedure according to volume of uterus $/ \mathrm{cm}^{3}$ and volume of dominant fibroid $/ \mathrm{cm}^{3}$ as $p$-value 0.015 , and 0.004 respectively and average uterine and dominant fibroid volumes loss of $61 \%$, and $79 \%$ respectively. These are consistent with the results of Liang et al., [13] that reported uterus and dominant fibroid volume $/ \mathrm{cm}^{3}$ ranged from $77-1767$, and 91-897 respectively and uterine and dominant fibroid volume reduction about $50 \%$, and $60 \%$ respectively. On the other hand, Tamara et al., [14] recorded average uterine and dominant leiomyoma volumes of 770 (range: $330-1193 \mathrm{~cm}^{3}$ ), 300.5 (range: 80 $500 \mathrm{~cm}^{3}$ ) respectively, and average uterine and dominant fibroid volume reduction were $30 \%$, and $44 \%$ respectively.

We had 15 (100\%) dominant fibroids enhanced in MRI with contrast pre UAE, and all became unenhanced after UAE; that indicating success of treatment and is statistically highly significant with $p$-value of $<0.001$. This is consistent with Liang et al., [13] study that showed $100 \%$ lack of enhancement, while Steven et al., [1s reported only $76 \%$ non enhancement post UAE.

Six months follow-up MRI after UAE revealed $1(6.7 \%)$ case with complication that presented with pyometra (uterine infection), and no fibroid regrowth, fibroid site changes, or uterine necrosis observed, in comparison to the results of Kim et al., [10] who reported $30 \%$ of patients had new leiomyomata formation. Verma et al., [16] stated 9\% change in site of the fibroids as a post UAE complication. Sangeet et al., [17] found that $2 \%$ of the patients had post embolization infection, and $1 \%$ had uterine necrosis.

Our study showed no significant correlation between the success of UAE with bleeding, pain, and pressure symptoms improvement score. Correlation absence with the presence of slight and significant improvement score of symptoms in some patients may be due to statistical chance or small sample size. While the correlation between uterine volume change percentage and improvement score of the fertility was precluded cause fertility state needs more than 6 months to show effective changes. Mutai et al., [18] study of (59) patients agreed with our results that reduction in fibroid size post procedure does not correlate with improved symptoms and quality of life because the peak imaging outcome appear at 3-6 months while the peak clinical outcome is at 6-24 months. In contrast Charles et al., [19] reported strong and significant positive correlation between uterine and dominant fibroid volumes change with bleeding, pain, fertility, and pressure symptoms improvements score and life quality improvement which is mostly due to larger number of patients (80) and longer time of follow-up (one year).

\section{Summary and Conclusion:}

Uterine fibroids are the most common benign tumours in women and accounts for the majority of hysterectomies in the world. Their effect range from heavy menstrual bleeding, pressure symptoms and pain up to infertility. Uterine Artery Embolization (UAE) is now evolving to be the first-line treatment for symptomatic uterine leiomyoma alongside the conventional surgical treatment of hysterectomy and myomectomy.

MR imaging performed before and after UAE is the best imaging modality to diagnose, map, and characterize fibroids, and it can detect their state of vascularity and degeneration, it also help to assess pathologies that may preclude UAE, or change the embolization protocol, such as the presence of adenomyosis.

Our study emphasize the important role of follow-up MRI after UAE that was obtained in 15 women. The mean uterine volume was significantly reduced by $61 \%$ ( $p$-value 0.015 ), the mean dominant fibroids volume significantly reduced by $79 \%$ ( $p$-value 0.004$)$ and the dominant fibroidsshowed significant lack of enhancement $100 \%$ ( $p$-value $<0.001)$ that indicted treatment success.

In addition our study showed the role of MRI in assessing the outcomes and complications as only $1(6.7 \%)$ patient detected with pyometra (uterine infection).

In this study we noted significant improvement of bleeding in $69.2 \%$ and of pain in $11.1 \%$ with slight improvement of pressure symptoms in $66.7 \%$, wetried toassesscorrelation between the percentage of uterine and dominant fibroid change with the symptoms improvement score of bleeding, pain, and pressure symptomsthat showed no significant correlation. While the fertility improvement score was precluded as it needs long time follow-up.

In our study, no case was recorded of recurrence/ residual fibroid tissue that was successfully excluded on follow-up MRI.

We found that the main lack in our study was the small number of patient included and short follow-up time (only 6 months). 
In conclusion we can say that MRI has important role in (1) Evaluation of UAE success through uterine and dominant fibroid volume reduction and lack of enhancement, (2) Evaluation of the outcomes and complications including fibroid regrowth, fibroid change site, pyometra and uterine necrosis.

We recommend further research on a larger number of patients and longer period of follow-up to confirm and had more strong results.

\section{References}

1- KHAN A.T., SHEHMAR M. and GUPTA J.K.: Uterine fibroids: Current perspectives. Int. J. Womens Health, 6: 95-114, 2014.

2- VILOS G., ALLAIRE C., LABERGE P. and LEYLAND N.: The Management of Uterine Leiomyomas. J. Obstet. Gynaecol. Can., 37 (2): 157-78, 2015.

3- WESTCOTT M.: Uterine Fibroid Embolization InKipshidze N., Fareed J., Rosen R., Dangas G. and Serruys P. Urgent Interventional Therapies. John Wiley \& Sons, Ltd, 1 st edition, 474-84, 2015.

4- PRITTS E.A., PARKER W.H., BROWN J. and OLIVE D.L.: Outcome of occult uterine leiomyosarcoma after surgery for presumed uterine fibroids: A systematic review. Journal of Minimally Invasive Gynecology, 22: 26-33, 2015.

5- LIANG E. BROWN B., KIRSOP R., STEWART P. and STUART A.: Efficacy of uterine artery embolization for treatment of symptomatic fibroids and adenomyosis-An interim report on an Australian experience. Australian and New Zealand Journal of Obstetrics and Gynecology, 52: 106-12, 2012.

6- MACIEL C., TANG Y., SAHDEV A., MADUREIRA A. and VILARES-MORGADO P.: Preprocedural MRI and MRA in planning fibroid embolization. Diagn. Interv. Radio., 1-9, 2016.

7- SIDDIQUI N., NIKOLAIDIS P., HAMMOND N. and MILLER F.: Uterine artery embolization: Pre-and postprocedural evaluation using magnetic resonance imaging. Abdom Imaging, 2013.

8- LOPES J. and MARGARIDA T.: MR and CT techniques. In Forstner R., Margarida T., Hamm B., eds. MRI and $\mathrm{CT}$ of the Female Pelvis, series Medical Radiology:
Diagnostic Imaging. Springer International Publishing, 1-13, 2017.

9- VERMA S.K., GONSALVES C.F., BALTAROWICH O.H., MITCHELL D.G., LEV-TOAFF A.S. and BERGIN D.: Spectrum of imaging findings on mri and ct after uterine artery embolization. Abdominal Imaging, 35: 11828, 2010.

10- KIM M., LEE H., LEE M., et al.: Long-term results of symptomatic fibroids treated with uterine artery embolization: In conjunction with MR evaluation. Eur. J. Radiol., 73 (2): 339-44, 2010.

11- HOMER H. and SARIDOGAN E.: Uterine artery embolization for fibroids is associated with an increased risk of miscariage. Fertil Steril., 94: 324-30, 2016.

12- GOLDBERG J., PEREIRA L., BERGHELLA V., et al.: Pregnancy outcomes after treatment for fibromyomata: Uterine artery embolization versus laparoscopic myomectomy. Am. J. Obstet. Gynecol., 191: 18-21, 2014.

13- LIANG E.Y., STUART A., SMIT D., et al.: MRI appearance before and after uterine artery embolisation for treatment of symptomatic fibroids and adenomyosis. RANZCR-AOCR, 81, 2012.

14- TAMARA M., SAMER M. and WAFAA R.: Measurement of uterine leiomyomata volume pre and post uterine artery embolization aided by MRI. The Egyptian Journal of Hospital Medicine, 71 (4): 3007-16, 2018.

15- STEVEN D., GARY M. and SHIRLEY M.: Comparison of four different embolic materials for uterine artery embolization in post-procedure MRI enhancement. Radiology, 250 (2): 482-7, 2009.

16- VERMA S.K., BERGIN D., GONSALVES C.F., et al.: Submucosal fibroids becoming endocavitary following uterine artery embolization: Risk assessment by MRI. AJR, 190 (5): 1220-6, 2018.

17- SANGEET G., DHEERAJ K., MATTHEW S., et al.: Uterine artery embolization for leiomyomas: Pre-and postproceduralevaluationwith US. Radio Graphics, 25 : 1159-76, 2015.

18- MUTAI J. VINAYAK S., STONES W., HACKING N. and MARIARA C.: Uterine fibroid embolization for symptomatic fibroids: Study at a teaching hospital in Kenya. J. Clin. Imaging Sci., 5: 18, 2015.

19- CHARLES M., TIMONA O., NIGEL H., et al.: One year symptom severity and health-related quality of life changes among Black African patients undergoing uterine fibroid embolisation. BMC Res. Notes, 10: 240, 2017. 


\section{دور الرنين المغناطيسى فى تقييم آورام الرحم الليفية بعد العلاج بواسطة إنصمام الشئريان الرقئ الرحمى الرحئ}

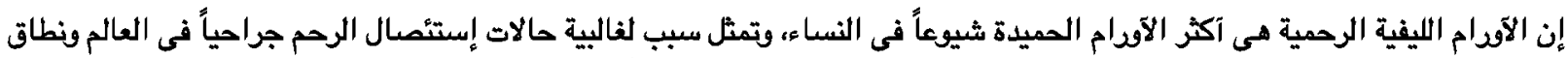

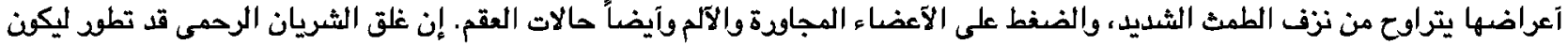

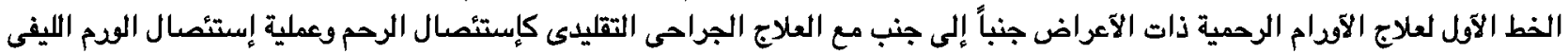

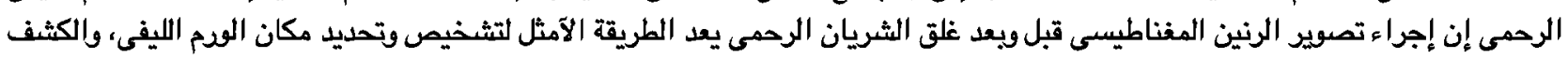

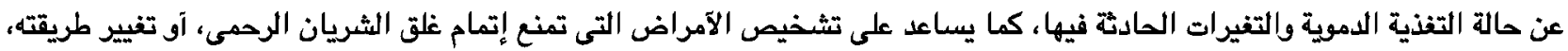

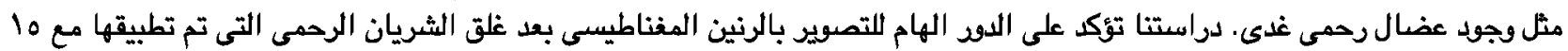

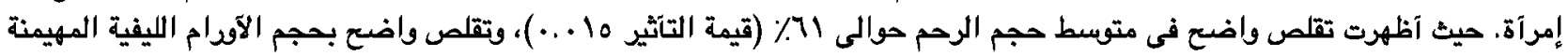

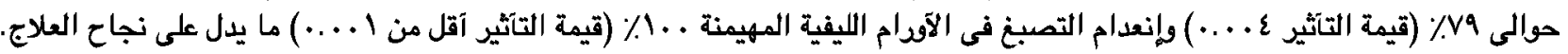

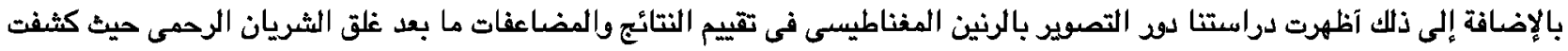

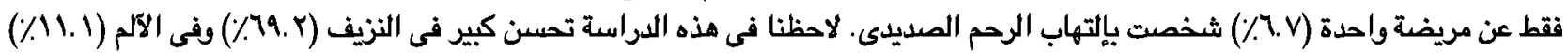

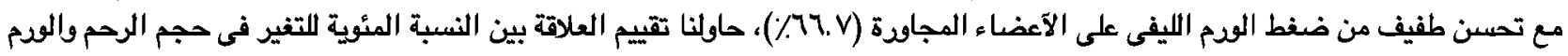

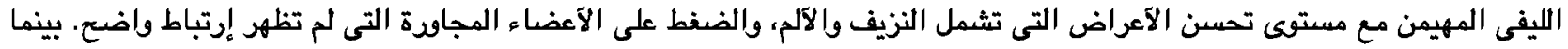

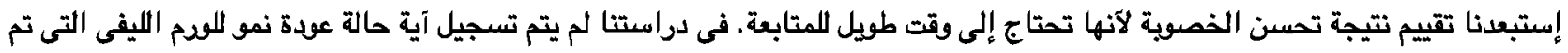

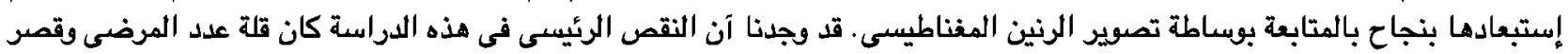

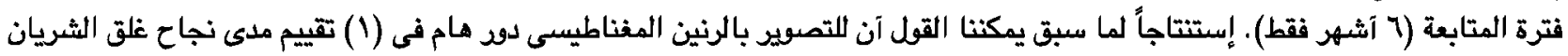

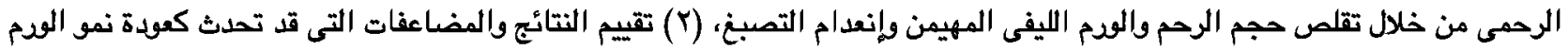

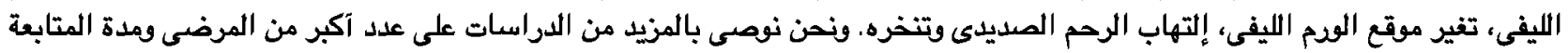

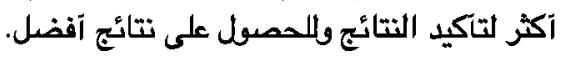

